\title{
Comparable Harm and Equal Inherent Value: The Problem of Dog in the Lifeboat
}

\author{
Gary L. Francione \\ Rutgers Law School
}

This essay is dedicated to my canine companions, Bandit, Stratton, Emma, Tedwyn, and Robert, who will always have a safe place in my lifeboat.

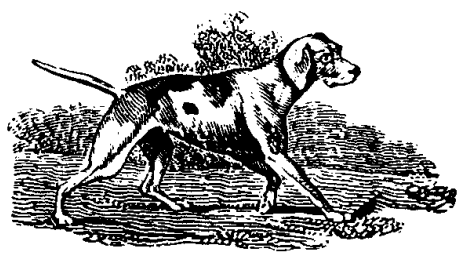

Introduction

In The Case for Animal Rights, Tom Regan posits the following hypothetical: five survivors-four normal adults and one normal dog-are on a lifeboat. There is room in the boat only for four, and one of the occupants must be thrown overboard. Regan maintains that his rights theory provides an answer to the problem. Although death is a harm for the dog, Regan argues, death would be a qualitatively greater loss, and, accordingly, a greater harm, for any of the humans: "To throw any one of the humans overboard, to face certain death, would be to make that individual worse-off (i.e., would cause that individual a greater harm) than the harm that would be done to the dog if the animal was thrown overboard." It would, on Regan's view, be morally obligatory to kill the dog. Further, Regan claims even if the choice is between a million dogs and one person, it would still be obligatory under rights theory to throw the dogs overboard.

This notion of comparable harm is not unique to Regan although different theorists use it in different ways. Other theorists who subscribe to some version of animal rights share Regan's view. For example, Joel

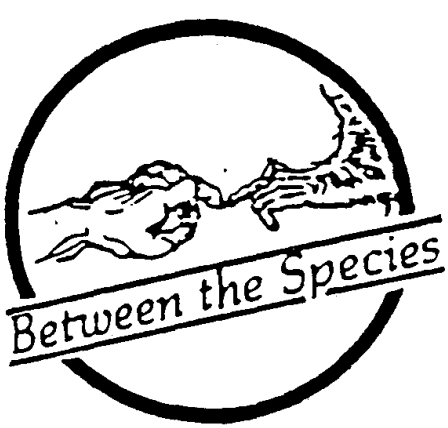

Feinberg argues that although animals have rights, the rights position is consistent with holding "that an individual human life as such is a thing of far greater value than an individual animal life as such."2 This view is also shared by those who work outside the rights paradigm; indeed, one of the few points of similarity between Regan's rights theory and the utilitarian theory of Peter Singer is that although both rely heavily on normative notions of equality, both appeal to the notion that some beings have qualitatively different and ultimately more valuable experience for purposes of resolving conflicts between beings who have moral standing. For example, Singer argues that "we can make sense of the idea that the life of one kind of animal possesses greater value than the life of another; and if this is so, then the claim that the life of every being has equal value is on very weak ground." 3

Reliance on notions of comparable value and harm by Regan, Feinberg, and Singer has occasioned critical reactions by friend and foe alike. For example, philosopher S. F. Sapontzis, who argues in favor of including animals as members of the moral community, takes issue with the hierarchical status of humans implied by the notion of comparable harm. Humans undoubtedly can experience things that animals cannot, but the opposite is true as well: "We cannot enjoy the life of a dog, a bird, a bat, or a dolphin."4 Accordingly, we cannot use species alone to make judgments of

(C) Copyright Gary L. Francione, 1995

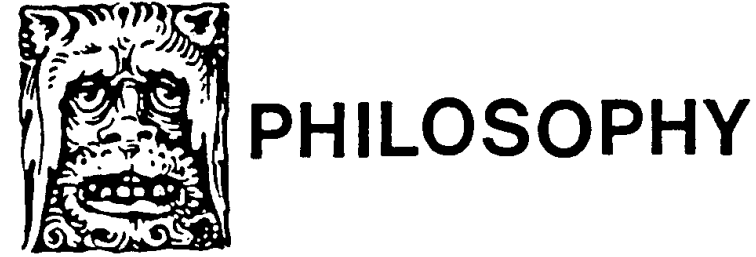


relative harm to resolve conflicts between humans and nonhumans without being guilty of the very speciesism that is the foundation of animal exploitation.

Peter Carruthers, who rejects the moral standing of animals, similarly bases his argument in very large part on Regan's and Singer's willingness to argue that human experience is such that humans generally suffer greater harm than do animals when humans are foreclosed from satisfying opportunities. Carruthers argues that we have a common-sense moral view that human life cannot be weighed against animal life that is so strong that even Regan and Singer affirm the validity of this view. Carruthers maintains that the moral theory that is most comfortably consistent with this common-sense view is some form of contractualism that would exclude animals from the moral community because animals are not rational agents. ${ }^{5}$

Ironically, one of Regan's most vocal critics is Singer, who claims that a "theory that tells us that all subjects-of-a-life (including dogs) have equal inherent value [cannot] be reconciled with the intuition that it is the dog that must be sacrificed." ${ }^{\circ}$ Singer argues that because Regan maintains that, in the lifeboat example, his theory would allow for the killing of a million dogs as well, Re'gan's theory would permit more animal use than Singer explicitly acknowledges would be permitted at least in theory under utilitarianism. Singer denies that individual capacities (intelligence, awareness) play a role in his assessments about the morality of imposing pain on animals although Singer's construction of "interests" is heavily dependent on those capacities. Singer thinks that dependence on these capacities may cut in favor of the animal (i.e., we ought to attach greater interest to the animal's interest in avoiding pain or suffering because the animal may feel greater fear than a human because of different cognitive capacities), but that is irrelevant. The point is that whether it does cut in favor of the animal or not is an empirical question, and Singer's theory allows for those capacities to matter and cannot delimit only those whose application will favor nonhumans. Singer explicitly relies on capacities in resolving issues about the morality of killing animals. This leads him to the view that since most farm animals, in Singer's view, are incapable cognitively of grasping that they have a "life," they can be consumed by humans if they are raised entirely outside of the practices known collectively as "factory farming" or as "intensive agriculture," and if they are slaughtered painlessly.
The use of comparable harm analysis presents serious difficulties for any theory that seeks to expand in any significant way the protection accorded to nonhumans. These difficulties affect both deontological and consequentialist theories (albeit in different ways). I will, for the most part, confine my remarks to Regan's theory in which the notion of comparable harm is central. I will first set out the context in which Regan develops his views on comparable harm. I will then explore the implications of the notion of comparable harm for rights theory. I will argue that Regan's resolution of the lifeboat example is inconsistent with a radical egalitarian theory, but I will suggest a reading of Regan's theory that places the lifeboat example in a different theoretical context.

\section{Equal Inherent Value and Comparable Harm}

The central part of Regan's rights argument begins with his introduction of the postulate that moral agents have a distinct moral value - inherent value - that is separate from any intrinsic value such as pleasure or preference satisfaction. This notion of inherent value is presented by Regan as the primary altemative to the utilitarian notion that individuals are receptacles whose value may be determined by aggregating the intrinsic value that attaches to their experience. Inherent value is also an alternative to perfectionist ethics. Moral agents with inherent value must possess that value equally or else the notion of inherent value may collapse into one of the "pernicious" 8 perfectionist theories of justice "according to which what individuals are due, as a matter of justice, depends on the degree to which they possess a certain cluster of virtues or excellences, including intellectual and artistic talents and a character that expresses itself in the performance of heroic or magnificent deeds." 9 Perfectionist theories are objectionable not only because they provide the "foundation of the most objectionable forms of social, political, and legal discrimination" but also because "[w] hether individuals have the talent necessary to acquire the favored virtues (e.g., ability to do higher mathematics) is beyond their control." 10

The attribution of equal inherent value to at least some moral patients (all normal mammals aged one year or more) is required because both agents and patients are subjects-of-a-life; that is, agents and patients are conscious, and possess a complex awareness (including beliefs and desires and an ability to pursue and satisfy 
them) and psychophysical identity over time. Agents and patients may be harmed or benefited and have a welfare in that their experiential life fares well or ill for them, independently of the utility that they have for others or the interest that others have in them. Being a subject-of-a-life is not only a sufficient condition for having inherent value but is also a criterion that allows for the intelligible and nonarbitrary attribution of equal inherent value to moral agents and moral patients, including nonhumans. Regan stresses that there is no nonarbitrary way to separate moral agents from moral patients and that there is no nonarbitrary way of differentiating nonhuman moral patients from their buman counterparts.

Regan's respect principle, a predistributive formal principle, requires that we treat those who have inherent value in ways that respect that value and holds that no individual with inherent value may be treated solely as a means to an end in order to maximize the aggregate of desirable consequences. From the respect principle we may derive the harm principle, which holds that, as a prima facie matter, harming the interests of a subjectof-a-life is showing disrespect for the inherent value of the moral agent or patient. In light of the prima facie nature of the obligations imposed by the harm principle, it is necessary to determine under what circumstances inflicting harm on moral agents or patients will be permitted. It is in this context that the notion of comparable harm becomes relevant.

Regan distinguishes two types of harm: harms that are inflictions and harms that are deprivations. "Acute or chronic physical or psychological suffering is the paradigm of a harm understood as an infliction." 11 Deprivations involve "losses of those benefits that make possible or enlarge the sources of satisfaction in life." 12 According to Regan, "whatever the category, not all harms are equal."13 Harms are comparable "when they detract equally from an individual's welfare, or from the welfare of two or more individuals." 14 Similarly, harms may not be comparable in those instances in which there are differential effects on the welfare of morally relevant beings. Although we may assume that there is a "strong presumption" that "like harms have like effect," the realities of individual variability require recognition that like harm may detract differently from individual welfare and may not be counted as comparable. ${ }^{15}$

This notion of comparable harm is the foundation for the two general principles that Regan uses to resolve conflicts. The "miniride" principle, which assumes that the morally innocent individuals involved will be harmed in a prima facie comparable way, holds that in such situations (and in the absence of special considerations) we should choose to override the rights of the few rather than to override the rights of the many. ${ }^{16}$ The "worseoff" principle, which assumes that the morally innocent individuals involved will suffer non-comparable harm, holds that in such situations (and in the absence of special considerations) we should choose to override the rights of the many when the "harm faced by the few would make them worse off than any of the many would be if any other option were chosen." 17

So, the notion of comparable harm (and its related concepts) plays a significant role in Regan's theory, since it specifies the circumstances under which harm may be inflicted on subjects-of-a-life, all of whom possess equal inherent value. In this context, Regan discusses the admittedly exceptional case of the four humans and the dog (or a million dogs) in the lifeboat. The dog has inherent value; indeed, according to Regan, the dog has inherent value that is equal to that possessed by her human co-passengers. Both the dog and the humans have a prima facie right not to be harmed. The decision to throw the dog overboard is not speciesist, Regan argues, because the decision to sacrifice the dog is not based on species membership but rather, "on assessing the losses each individual faces and assessing these losses equitably." 18 There is no aggregating of harms in that the rights view would require throwing one million dogs overboard to save the four humans. Although the dogs are subordinated to the humans, this does not mean that there should be any "routine subordination of the less virtuous by those who are more virtuous, so that the latter may develop their virtues optimally. The rights view disallows such subordination." 19 The lifeboat case is an exceptional case and "what the rights view implies should be done in exceptional cases... cannot fairly be generalized to unexceptional cases."20

\section{Harm as an Empirical Matter, "Routine" Subordination, and the "Exceptional" Case}

From the above description of certain aspects of Regan's theory, it is clear that Regan very explicitly rejects any sort of perfectionism in favor of radical egalitarianism. Regan's postulate of equal inherent value is, according to Regan's own description, "categorical" and 
"admitting of no degrees." 21 That is, Regan rejects the notion that individuals can have different degrees of inherent value: "If moral agents are viewed as having inherent value to varying degrees, then there would have to be some basis for determining how much inherent value any given moral agent has. " ${ }^{2}$ A theory of differing levels of inherent value would risk reliance on some version of perfectionism, which Regan rejects.

In addition, the attribution of equal inherent value to moral agents and moral patients alike rests on the notion of the subject-of-a-life, which Regan also recognizes as categorical ${ }^{23}$ Indeed, the concept must be categorical; if beings could possess status as a subject-of-a-life to varying degrees, then it might be possible that only moral agents-and not moral patients-would have that status. But Regan rejects this notion in favor of an egalitarian criterion that "does not assert or imply that those who meet it have the status of subject of a life to a greater or lesser degree, depending on the degree to which they have or lack some favored ability or virtue (e.g., the ability for higher mathematics or those virtues associated with artistic excellence). One either is a subject of a life, in the sense explained, or one is not. All those who are, are so equally." 24

In order to be a subject-of-a-life, a being need only be sentient, possess beliefs and desires (and an ability to act in pursuit of desires and goals), perception, memory, a psychophysical identity over time, emotional life, and experiential welfare that is better or worse depending on what happens to that being. Because both moral agents and moral patients are subjects-of-a-life "one cannot nonarbitrarily maintain that how much inherent value moral agents have depends on the degrees to which they possess the virtues in question or on how much utility for others they have. 25

Although both equal inherent value and the criterion used to attribute that value to moral agents and moral patients are categorical, the concept of harm apparently is not categorical, in that Regan allows supposed differences between humans and nonhumans to rebut the "strong presumption" that "like harms have like effects." As between the human and nonhuman occupants of the lifeboat, the same harm is deemed to be qualitatively different. Regan defends his theory of comparable harm in three ways. First, he maintains that there is, as an empirical matter, a difference between the harm suffered by the human and the same harm suffered by a nonhuman. Second, he argues that perfectionist ethical theories would permit "the routine subordination of the less virtuous by those who are more virtuous." 26 Third, he argues that "prevention cases, including lifeboat cases, are exceptional cases." 27

I want to discuss briefly the empirical nature of harm determinations, the notion of "routine" subordination, and the problem of identifying "exceptional" circumstances.

\section{(a) harm as an empirical matter}

Regan regards both the postulate of equal inherent value and the criterion used to attribute that value to moral agents and patients (all subjects-of-a-life) as categorical and admitting of no degrees whatsoever. Harm, however, is different. Although there is obvious overlap, we can, as an empirical matter, identify at least two types of harm-inflictions and deprivations-and we may, also as an empirical matter, judge that different rightholders may be affected in different ways by the same type of harm.

The problem with regarding harm as an empirical matter is that it involves a different analysis from that involved in the formulation of Regan's theoretical postulates. Not only is it difficult as an empirical matter to make some of the assessments that need to be made to compare harms, but, more important, any such consideration of supposed empirical facts about harm in this regard is inconsistent with what it is necessary to disregard in the formulation of those theoretical postulates. Regan carefully constructs his postulate of equal inherent value so that it excludes any notion of individual characteristics or what may be thought to be virtues in a perfectionist theory. Similarly, his subjectof-a-life criterion similarly excludes any notion of individual characteristic or virtue apart from those characteristics-sentience, beliefs, desires, psychophysical identity over time-that are constitutive of subject-of-a-life status. In light of the obvious empirical differences among human beings, and between humans and animals, Regan could have developed a concept of "subject" that reflected those differences. But he avoided these characteristics in favor of categorical theoretical notions that disregarded as irrelevant the existence of these empirical differences.

If the status of being a subject-of-a-life is, as Regan argues, an all-or-nothing proposition, then all such subjects must be equal for purposes of deciding at least those conflicts that involve interests protected under 
the rights theory. If all rightholders have inherent value because to accord them differential value would lead to perfectionism, and if moral agents and patients alike have this equal value because to accord them differential value would lead to perfectionism, then accepting a theory of comparable harm based at least in part on the presence or absence of certain virtues may be the same as arguing that the being who is harmed less has an inherent value that is different from, and less than, the one harmed more. Indeed, in Singer's theory, the different quality of experience is used primarily to determine relative value of different beings and not to differentiate the varying degrees of harm suffered by beings with the same inherent value. ${ }^{28}$

\section{(b) "routine" subordination}

Part of the difficulty surrounding the notion of comparable harm is related to ambiguity involving precisely what constitutes "routine" subordination and when we have an "exceptional" case. When Regan says that the lifeboat example does not involve the "routine" subordination of one subject of a life to another, he means that the principle that we should favor humans over the dog is not one that we should apply save in "exceptional" circumstances. A routine subordination in unexceptional cases would likely represent some form of perfectionism. Indeed, Regan argues that the postulate of equal inherent value is acceptable because it avoids the "wildly inegalitarian implications of perfectionist theories." 29 Moreover, Regan rejects any attempt to argue that moral patients (including nonhumans) have less inherent value than moral agents on the grounds that such an argument would require, inter alia, reliance on perfectionist notions such as intellect or artistic ability, etc. ${ }^{30}$

The problem is that even if the lifeboat example is the only or the primary example of the "exceptional" case, it still represents a form of perfectionism. If, for example, all cases were lifeboat (or otherwise "exceptional") cases, and all of these exceptional cases involved normal, healthy humans and normal, healthy dogs, then the prescription for resolving those cases would require that we regard the harm to the dogs as incomparable with the harm suffered by the humans because of a supposed excellence enjoyed by the latter to a greater degree: humans have a qualitatively greater opportunity for satisfaction that is foreclosed by action that is detrimental to them.
Regan argues that even in the lifeboat case, the decision to kill the dog is not based on any appeal to perfectionist theories but, rather, is based on consideration of the equal inherent value and equal prima facie right not to be harmed. Although Regan may be correct to argue that his resolution of the lifeboat example does not appeal explicitly to perfectionism as advocating the routine subordination of rightholders, his resolution does appeal to a supposed human "excellence" (the ability to pursue opportunities for satisfaction). But to say that this virtue may be appealed to only in exceptional cases is nevertheless to say that in that class of cases, there is routine subordination based on a supposed virtue possessed by one class of rightholders.

\section{(c) "exceptional" circumstances}

The third problem involved in using comparable-harm analysis involves delineating those circumstances in which the analysis will apply. Although Regan talks of "exceptional" circumstances, it appears as though the miniride and worse-off principles are intended to be principles to resolve conflict as a general matter. And, in morality, conflict is the rule and not the exception. To the extent, then, that comparable-harm analysis is to be applied in any situation of conflict between or among rightholders, then the result in the lifeboat situation portends difficulties for an animal rights theory. The use of a putative human excellence to justify the killing of the dog in the lifeboat example opens the door to perfectionist ethical theory in that any such consideration, it seems, detracts from the notion of equal inherent value, which rests, at least in part, on the notion that possession of inherent value depends only on the status of the individual as a subject-of-a-life with consciousness, complex awareness, and a psychophysical identity over time. To the extent that we regard harms to normal, healthy rightholders as incomparable, we depart from the presumption that Regan establishes that we should assume that like harms have like effects on rightholders.

Even if, however, the comparable-harm analysis applies only to truly "exceptional" cases, it is difficult to know exactly what cases are covered. For example, Sapontzis argues that it is improper to use animals in medical experiments except when animal use (and perhaps the use of comatose or terminally ill humans) is "necessary for and greatly outweighed by some clear 
and present, massive, desperately needed good." 31 How close is this situation to the lifeboat example? Does it qualify as an "exceptional" case? If so, it would seem that even a rights advocate could justify using animals (or "marginal" humans) based on the differential "excellence" possessed by normal humans whose use for the purpose would foreclose more opportunities for satisfaction.

The preceding discussion indicates that a reliance on comparable-harm analysis is problematic not only because it may entail speciesist conclusions. Let us return to the lifeboat. There are five survivors-all human. Four of the survivors possess some sort of extraordinary talent-one is a gifted musician, one a genius mathematician, etc. The fifth survivor is a normal, healthy adult who works at a minimum wage job and possesses no special skill or talent. If we can depart from the assumption that like harms have like effects when the fifth passenger is a dog, why not assume that the like harm of death will have a different impact on the four talented survivors than it will on the fifth untalented survivor because death for the former will foreclose opportunities for satisfaction in a way that it will not for the latter?

\section{“Exceptional” Circumstances and Basic Rights}

There is, however, an important sense in which the real difficulty with the lifeboat example is that Regan mentions it at all. Although Regan thought that bis general theory of animal rights provided an answer for the lifeboat situation, he may have made the mistake of confusing a question concerning the rights that animals would have in a situation in which animal rightholders had a conflict with human rightholders with a general theory that concerned only the question of whether animals had a single right not to be treated solely as means to ends.

It is my view that Regan never intended The Case for Animal Rights as an exhaustive analysis of every issue-including how to resolve conflicts between rightholders - that flowed from the recognition that animals have rights. Regan's primary focus was on the violation of animal rights through their treatment solely as means to human ends in institutionalized exploitation represented by factory farming, vivisection, and animal use for clothing and entertainment. That is, Regan argued that animals ought to be included in the class of rightholders, and that in order for membership in this class, it is necessary that we recognize the basic right of animals not to be treated as property, or, as Regan puts it, not to be treated exclusively as means to human ends.

Although the notions of "basic" and "absolute" rights are discussed in much philosophical literature, its most lucid presentation for present purposes may be found in the analysis presented by Professor Henry Shue in his book, Basic Rights. ${ }^{32}$ According to Shue, a basic right is not a right that is "more valuable or intrinsically more satisfying to enjoy than some other rights." 33 Rather, a right is a basic right when "any attempt to enjoy any other right by sacrificing the basic right would be quite literally self-defeating, cutting the ground from beneath itself." Shue states that "non-basic rights may be sacrificed, if necessary, in order to secure the basic right. But the protection of a basic right may not be sacrificed in order to secure the enjoyment of a nonbasic right." The reason for this is that a basic right "cannot be sacrificed successfully. If the right sacrificed is indeed basic, then no right for which it might be sacrificed can actually be enjoyed in the absence of the basic right. The sacrifice would prove self-defeating." Shue emphasizes that basic rights are a prerequisite to the enjoyment and exercise of non-basic rights, and that the possession of non-basic rights in the absence of basic rights is nothing more than the possession of rights "in some merely legalistic or otherwise abstract sense compatible with being unable to make any use of the substance of the right." 34

In order for animals to enjoy any rights at all, it is first necessary that they stop being regarded as "things" which, as a matter of law and (some) moral theories, cannot have rights. For example, the law regards animals as property, and "legal relations in our law exist only between persons. There cannot be a legal relation between a person and a thing or between two things." 35 Property "cannot have rights or duties or be bound by or recognize rules." 36 Regan's enterprise may be understood as an argument in favor of the single, basic right not to be regarded as property. A right to be treated as a moral and legal person is perhaps the most basic right in that personhood is a necessary condition of having relations at all in any normative system that distinguishes between persons and things.

Regan's theory of animal rights is similar to theories about the abolition of human slavery, which concerned the basic right of human beings not to be regarded as the property of others. Those who opposed 
slavery argued that it was morally wrong to treat human beings exclusively as means to the ends of other humans. But the abolitionist position did not entail what particular rights would be possessed by the liberated slaves-other than the basic right not to be regarded as property. Regan is concerned about institutionalized animal exploitation, and it is this concern that led him to reject "routine" subordination and to use of the miniride and worse-off principles in only "exceptional" circumstances.

An important part of Regan's theory is that all forms of institutionalized exploitation of animals violate the respect and harm principles because they fail to treat individuals as possessing equal inherent value, and rely on some form of utilitarian or perfectionist thought. For example, a slave owner could not rely on the worse-off or miniride principles to complain of harm when a slave was liberated against the owner's will. In this sense, then, Regan might have a way of distinguishing exceptional or extraordinary cases from most others in that some involve institutionalized animal exploitation that Regan would argue is from the outset violative of animal rights. Regan's theory would conceptually prevent there being a conflict from the outset in such situations. Regan could argue consistently that rights theory conceptually prevents our making any sort of comparable-harm determination in the context of animal use (or the use of "defective" humans) to find a cure for the most serious epidemic. Such animal use would entail institutions that are inherently exploitative of animals because they regard animals solely as means to human ends. This option is not open to Singer, who, if he is to be consistent, must inquire as to whether any exploitation-institutionalized or not - is justified by the principle of utility. For Singer, all cases are lifeboat cases. For Regan, exceptional cases exclude the institutionalized treatment of rightholders solely as means to the ends of others.

If this interpretation of Regan is correct, then two things are now clear. First, it was wholly unnecessary for Regan even to discuss the lifeboat example. Regan applies the miniride and worse-off principles to the lifeboat example, which, by Regan's own and explicit account, indicates that we are dealing with a situation in which there is no institutionalized exploitation operative, so the case does not concern the matter that is the primary subject of Regan's analysis. Regan's resolution of the lifeboat example is not required by his overall theory because the lifeboat example concerns a very different contextthe resolution of a conflict between two rightholders-from the one that occupies Regan's attention throughout The Case for Animal Rights-the inclusion of nonhumans in the class of rightholders. Regan thought that his general theory provided an answer to the lifeboat situation, and this may have resulted from confusing issues concerning conflicts between rightholders with issues concerning membership in the class of potential rightholders.

Second, to the extent that Regan's (unnecessary) resolution of the problem requires the use of some form of perfectionism, such a requirement is problematic for Regan's overall theory, but not for the reasons pointed to by his critics. Regan could say that although all beings with inherent value possess that value equally for purposes of not treating any being exclusively as a means to an end in institutionalized exploitation, these beings do not possess the same value for purposes of resolving conflicts between rightholders. This reflects our intuition that it may be permissible to award Mary a scholarship if she is better in math than Johnny, but that it is not permissible to enslave Johnny for Mary's use simply because he is less intelligent than she.

The problem is that in light of Regan's analysis of the lifeboat example, it would seem that he is committed to resolving virtually every human/animal conflict in favor of the human. This does not, as some have suggested, mean that he is on a slippery slope back to vivisection. On the contrary, Regan can claim that the respect principle is always violated in cases of institutionalized exploitation. But it does give nonhumans a somewhat pyrrhic victory. Animals may no longer be regarded as property, but their interests will nevertheless not prevail most of the time because the characteristics upon which we relied to justify their property status will now be used to resolve any conflict that they may have as rightholders with a human rightholder.

Once animals are no longer treated as property, then it will become necessary to determine what particular rights are or should be possessed by animals. At this juncture, it may be permissible to take the presence or absence of certain virtues to resolve conflicts between or among rightholders. It is, however, problematic to say that rights theory requires that we throw the dogor a million dogs-overboard, just as it would be problematic to say that a human rights theory about the 
abolition of human slavery requires that we always throw overboard the human with the least intelligence.

Perfectionism in the context of deciding issues or conflicts involving at least basic rights raises serious problems for any theory that rests on a notion of radical equality. My ability to do mathematics may legitimately be used to decide whether I get a math scholarship; that ability is irrelevant to whether, in a situation of famine, I should get the one remaining crust of bread. Respect for my basic or fundamental rights (however understood) should not, on a radical egalitarian view, depend on my virtues, which are, in any event, out of my control for the most part. To the extent that Regan links even basic rights (other than the right not to be property) with the possession of certain "virtues," he allows for differential consideration of equal inherent value. Such differential consideration would not justify using animals in experiments or otherwise relegating them to property status, but it might very well mean that animals will continue to lose in virtually every situation in which their "rights" were found to conflict with those of humans.

In order for Regan to escape this difficulty, he needs a theory about basic rights other than the right not to be property. Once individuals are determined to possess equal inherent value, then any conflict involving basic or fundamental rights ought to be decided without reference to any particular "virtue," which is what comparable harm analysis prescribes ${ }^{37}$ Alternatively, Regan needs a theory about why the basic right not to be property is different from other basic rights. Regan would have to defend the notion that the harm of being treated exclusively as a means to an end is somehow different in a morally significant way from the harm of being deprived of other basic rights. One possible option is for Regan to argue that the right not to be property is the most basic of all rights because as long as a being is characterized as property, that being will be unable to enjoy those other rights as protected interests if virtually all interests are considered as tradable. The problem is that Regan never addressed this issue and never explicitly recognized that his theory was more about the abolition of animal slavery than a general theory of rights that animals would possess once they were no longer regarded as human property. Moreover, it is not clear that such a difference would be significant morally in comparison to deprivation of other basic rights, such as a minimal right of physical security or minimal subsistence.

\section{Conclusion}

In sum, the observation that Singer, Carruthers, and others have made of Regan's theory-that the lifeboat example sinks, as it were, the whole theory because it allows for a necessary compromise of the categorical nature of Regan's concepts of equal inherent value and subject-of-a-life-is incorrect. Regan's overall rights theory is not threatened by his compromise of his categorical concepts as long as the "exceptional" circumstances in which this compromise can occur are limited to those that are identified exclusively by reference to those categorical concepts. That is, "exceptional" circumstances can never include institutionalized exploitation so, irrespective of the emergency, such as a plague, performing animal experiments (a form of institutionalized exploitation) would always be deemed to violate the respect principle. Regan can retain comparable-harm analysis, but he cannot, it seems, accept any sort of "perfectionism," even in the exceptional case, insofar as basic rights are concerned.

Regan's resolution of the lifeboat example was unnecessary because it did not concern the general context of his theory, which involved only the basic right not to be treated exclusively as a means to an end. The lifeboat example concerns a conflict between rightholders. To the extent that in such situations Regan would require choosing the human interest over the animal interest, it is problematic for his theory because it would mean that animals, although no longer property, will virtually never prevail in any conflict with human rightholders. ${ }^{38}$

I gratefully acknowledge helpful comments received from Anna Charlton, Esq., co-director of the Rutgers Animal Rights Law Center, Priscilla Cohn, Professor of Philosophy at Penn State University, Tom Regan, Professor of Philosophy at North Carolina State University, and Steve Sapontzis, Professor of Philosophy at California State University.

\section{Notes}

1 Tom Regan, The Case for Animal Rights (Berkeley \& Los Angeles: University of California Press, 1983), p. 324.

2 Joel Feinberg, "Human Duties and Unborn Generations," in Rights, Justice, and the Bounds of Liberty (Princeton, N.J.: Princeton University Press, 1980), p. 203. 
${ }^{3}$ Peter Singer, Practical Ethics (Cambridge: Cambridge University Press 1979), p. 90.

${ }^{4}$ S. F. Sapontzis, Morals, Reason, and Animals (Philadelphia, PA: Temple University Press, 1987), p. 219.

${ }^{5}$ Peter Carruthers, The Animals Issue (Cambridge: Cambridge University Press, 1992), p. 9.

${ }^{6}$ Peter Singer, "Ten Years of Animal Liberation," The New York Review of Books, January 17, 1985, p. 49.

${ }^{7}$ Peter Singer, Animal Liberation, $2 \mathrm{~d}$ ed. (New York: New York Review of Books, 1990), pp. 228-30.

${ }^{8}$ Regan, supra, p. 234.

${ }^{9}$ Idem, pp. 233-34.

${ }^{10}$ Idem, p. 234

"Idem, p. 94.

${ }^{12}$ Idem, p. 97.

${ }^{13}$ Idem, p. 303.

${ }^{14}$ Idem, p. 304.

${ }^{15}$ Loc. cit.

${ }^{16}$ Idem, pp. 305-07.

${ }^{17}$ Idem, p. 308.

${ }^{18}$ Idem, p. 325

${ }^{19}$ Loc. cit.

${ }^{20}$ Loc. cit

${ }^{21}$ Idem, p. 244

${ }^{22}$ Idem, p. 236

${ }^{23}$ Idem, p. 244.

${ }^{24}$ Idem, pp. 244-45.

${ }^{25} \mathrm{Idem}$, p. 240.

${ }^{26}$ Idem, p. 325.

${ }^{27}$ Loc. cit.

${ }^{28}$ Singer, supra, pp. 88-90.

${ }^{29}$ Regan, supra, p. 247.

${ }^{30}$ Idem, p. 240.

${ }^{31}$ Sapontzis, supra, p. 224.

${ }^{32}$ Henry Shue, Basic Rights (Princeton, N.J.: Princeton University Press, 1980).
${ }^{33}$ Idem, p. 20.

${ }^{34}$ Idem, p. 19.

${ }^{35} \mathrm{C}$. Reinhold Noyes, The Institution of Property (New York: Longmans, Green \& Co., 1936), p. 290, n. 13 (quoting Restatement of the Law of Property (St. Paul, Minn.: American Law Institute, 1936)). See also Gary L. Francione, Animals, Property, and the Law (Philadelphia, PA: Temple University Press, 1995).

${ }^{36}$ Jeremy Waldron, The Right to Private Property (Oxford: Clarendon Press, 1988)

${ }^{37}$ It may also be the case that inflictions should be treated differently from deprivations. Although there may be a good deal of overlap here, it seems that inflictions concern harms that are more related to basic rights.

${ }^{38}$ It appears as though Regan may have modified his intuition slightly about the lifeboat example. Although he has not addressed the specific issue, in a reply to Singer's comments, he described the lifeboat example and asked whether "it would be wrong to throw the dog overboard in these dire circumstances?" and not whether it would be "obligatory" to do so. He argues that the judgment may very well rely on the moral agent's assessment of the differing capacities of the lifeboat occupants. Letter from Tom Regan to the Editor, The New York Review of Books, April 25, 1985. But that is very different from saying that it is obligatory to throw the dog overboard. 